\title{
Evaluation of the antimicrobial effect of Thymus capitatus Essential Oil (EO) Extract on Bacteria Isolated from Urinary Tract Infection
}

Lamya F. A. El-jalel ${ }^{1 *}$, Hanan A. Idris ${ }^{2}$, Aisha Eltagori ${ }^{3}$, Mohamed M. M. Bumadian ${ }^{4}$, Ismaeel H. Bozakouk ${ }^{4}$, Mariam H. Gonaid ${ }^{5}$, Abdlmanam Fakron ${ }^{6} \&$ Idress Hamad Attitalla $^{7}$

${ }^{I}$ Department of Environment, ${ }^{2}$ Department of Forests and Pastures, ${ }^{1,2}$ Faculty of Natural Resources and Environmental Sciences, Libya. ${ }^{3}$ The Central Medical Laboratory, Garyounis Campus, University of Benghazi, Libya. ${ }^{4}$ Microbiology Department, Faculty of Science, University of Benghazi, Libya. ${ }^{5}$ Pharmacognosy Department, Faculty of Pharmacy, University of Omar Al-Mukthar, Libya. ${ }^{6}$ Department of Microbiology, Faculty of Science, University of Omar Al-Mukthar, Al-Bayda - Libya. ${ }^{7}$ Department of Lab Medicine, Faculty of Medical Technology, Omar Al-Mukhtar University, Al-Bayda - Libya.

DOI: http://doi.org/10.38177/AJBSR.2021.3305

Copyright: () 2021 Lamya F.A.El-jalel et al. This is an open access article distributed under the terms of the Creative Commons Attribution License, which permits unrestricted use, distribution, and reproduction in any medium, provided the original author and source are credited.

Pathogenic bacteria recently turned to be increasingly resistant to the most commonly used antibiotics, thus it becomes an essential need to find another active component that participates in controlling pathogens harms. Thymus capitatus is an endemic aromatic medical plant wildly distributed in the Libyan Green Mountain; therefore, $T$. capitatus extracted essential oil was used to evaluate the antimicrobial activity. T. capitatus was chemically analyzed to determine the antimicrobial active components using Gas Chromatography-Mass Spectrometric techniques (GC/MS). The plant represented twenty-one chemical compounds including Alpha-thujenes, Gamma-terpinen, Carvacrol, Thymol, Trans-caryophyllene, Aroma dendrene, Alpha-humulene, Ledene, Gamma cadinene, Delta-cadinene, (-)-spathulenol, Caryophullene oxid, Alpha cadinol, Iso aromadrene epoxide, Cis-alpha bisabolene, Vulgarol B, 2-ethyl-4-methyl anisole, Hexanoic acid, oct-3-en-zylester, Phenol 1, 2, 3, 5, 6 tetramethyl and Anisole The antimicrobial activity of $T$. capitatus aromatic essential oil (EO) was analyzed on several types of pathogens using serial aromatic oil dilutions including $(50 \%, 25 \%, 13 \%, 6 \%$ and $3 \%)$. The results showed 50\% oil dilution is the most effective concentration for all tested pathogens including Escherichia coli 7839 ATCC; Klebsiella pneumoniae 700603 ATCC; Staphylococcus aureus 12973 ATCC and Enterococcus faecalis 12697 ATCC with an average diameter of inhibition zone was $28 \mathrm{~mm}$. The same oil concentration (50\%) showed antimicrobial effect against pathogenic bacteria isolated from urinary tract infection including S. saprophyticus, E. faecalis, E. coli; and K pneumonia with an average diameter of inhibition zone was $26 \mathrm{~mm}$. Our study may contribute to initial knowledge and would help to discover substances with potential therapeutic uses.

Keywords: Thymus capitatus, Antimicrobials, Gas chromatography-mass spectrometry.

\section{Introduction}

The Jabal Al Akhdar region includes several types of aromatic plants that grow wildly, which is considered a natural wealth that must be preserved and utilized from the most important of these plants. The genus of Thymus is one of the largest and most economically significant in the family Lamiaceae (Labiatae). Hundreds of species of the genus of Thymus found overall the arid, cold and temperate regions north of the equator (Morales 1989, 2002) Many studies have been done on the chemical content of volatile oils extracted from thyme to find out the chemical components, their concentrations and their effect on germs as mentioned by both (Korousou et al., 2005; Mathew et al., 2008; Kailel et al., 2007).

It has traditionally been used fresh or dried as a spicy herb, and also for medicinal uses against many ailments such as respiratory and digestive disorders (Pottier-Alapetite 1981; Jafri and El-Gadi 1985; Le Floch and Boulos 2008); because, prescription drugs are becoming too expensive, especially in developing countries (Shariff. 2001). Moreover, increasing the ability of microorganisms to resist antibiotics. In general, bacteria have a genetic ability to acquire and transmit resistance to drugs, which are used as therapeutic agents. (Cohen.1992). Qaraleh et al., 2009 studied the in vitro antibacterial activity of Thymus capitatus in Jordan.

The study concluded that the antibacterial activity of these extracts against bacteria was evaluated using the disc diffusion method. The results showed that the leaves had stronger antibacterial activity than the stem extracts. The 
Asian Journal of Basic Science \& Research Volume 3, Issue 3, Pages 39-46, July-September 2021

ethanolic extract had the highest yield and higher antibacterial activity than all other solvents. Compounds could be the main active compounds in this plant. Moreover, the antibacterial activity of ethanol leaf extract (LEE) was compared with that of essential oil (LEO) leaf extracts of $T$. capitatus. LEO showed greater antibacterial activity than LEE. LEO showed a wide range of antibacterial activity and Pseudomonas aeruginosa Mehrgana et al., 2008 studied the antibacterial activity of the thymus.

In another study, the methanolic extract demonstrated antibacterial activity against Gram-positive bacteria including Staphylococcus aureus, MRSA, Streptococcus pyogenes, Enterococcus faecalis, Vancomycin-resistant Enterococcus faecalis (VRE), and Micrococci. Furthermore, it showed no activity against Gram-negative bacteria, such as Escherichia coli, Pseudomonas aeruginosa and Salmonella spp. Habibi et al., 2015 studied the antibacterial activity of selected Libyan medicinal plants against Pseudomonas aeruginosa and Escherichia coli. Thymus capitatus does not affect Pseudomonas aeruginosa.

Thymus capitatus caused inhibition at $100 \mathrm{mg} / \mathrm{ml}$. Moreover, the minimum inhibitory concentration was $200 \mathrm{mg} / \mathrm{ml}$ for other plant extracts. The minimum inhibitory concentration for Pseudomonas aeruginosa was $50 \mathrm{mg} / \mathrm{ml}$ for Rhus tripartita extract, $100 \mathrm{mg} / \mathrm{ml}$ for Thymus capitatus and $200 \mathrm{mg} / \mathrm{ml}$ for the other tested plant extracts. A study was conducted by Jayari et al., 2017 to study the antibacterial activity of Thymus capitatus and Thymus algeriensis essential oils against four foodborne pathogens inoculated in ground beef.

The study was conducted on the antibacterial activity of essential oils extracted from Thymus capitatus and Thymus algeriensis against Escherichia coli, Salmonella typhimurium, Staphylococcus aureus, and Pseudomonas aeruginosa, the disk method showed that Thymus capitatus EO has a strong antibacterial effect, whereas Thymus algeriensis EO showed temperate efficiency.

This study aims to indicate the chemical content for the essential oil of wild thyme and examine its effect on the activity of some types of pathogen bacteria.

\section{Material and Methods}

\subsection{Preparation and Sampling}

Thymus capitatus has high distribution into the Al Jabal Alkhadr area, the plant parts used in this study was collected during the period March to June including the homogenized mixture of leaves, stems and flower buds. The plant was dried for seven days away from the sunlight, then it was ground to make it powder and saved into a sterile plastic page and saved in $-20{ }^{\circ} \mathrm{C}$ until further use.

\subsection{Thymus capitatus essential oil extraction}

The essential oil (EO) was extracted by hydrodistillation through mixing100gm of the dried plant with $500 \mathrm{ml}$ of $\mathrm{dH} 2 \mathrm{O}$ using a modified Clevenger type apparatus for essential oils extraction for 3 hours. To determine the minimum inhibitory concentration (MIC), Ethyl alcohol dilutions of the essential oil extraction were prepared including $(50 \%, 25 \%, 13 \%, 6 \%$ and 3\%) plus negative control (alcohol). The extracted oil and its dilutions were preserved into sealed dark glass bottles at $2-5^{\circ} \mathrm{C}$ prior to analysis. 


\subsection{Bacterial Isolates}

Different clinical pathogenic bacterial isolates from urinary tract infection were used to be tested for their susceptibility to the active chemical components extracted from Thymus capitatus. The antimicrobial activity of the plant oil extract was tested on a selection of bacterial serotypes including Escherichia coli 7839 ATCC; Klebsiella pneumoniae 700603 ATCC; Staphylococcus aureus 12973 ATCC and Enterococcus faecalis 12697 ATCC.

\subsection{Thymus capitatus essential oil antimicrobial effectiveness}

To investigate the antimicrobial activity of the $T$. capitatus essential oil, a few colonies 3-5 from fresh overnight pure bacterial cultures were mixed with normal saline to make a suspension prepared to meet the proper bacterial cell count on the agar plate according to $0.5 \mathrm{McF}$ arland standardization. Sterile cotton swabs were submerged into the bacterial suspensions and then swabbed on dried Mueller-Hinton agar plates. As same as the number of the essential oil dilutions and using 6 millimeters of cork borer, the number of wells was made into the agar plates containing bacterial sample including negative control. All the wells were filled with $100 \mu 1$ of the essential oil dilutions and incubated aerobically at $37 \mathrm{C}^{\circ}$ for 24 hours. The next day the antimicrobial activity was evaluated and the resulted diameter inhibition zones were measured in millimeters.

\subsection{Analysis of the T. capitatus (EO) using (GC/MS)}

For separating, identify and quantify chemicals that are involved in antimicrobial activity, the extracted $T$. capitatus essential oil was analysed using (GC/MS) technique. The analysis process was completed at the Central Laboratory of Residue Analysis of Pesticides and Heavy Metals in Food (QCAP Lab), Egypt, according to the modified method by Adams (2007).

\section{Results}

To determine and identify the active components of Thymus capitatus that participate in the antimicrobial susceptibility, a Gas Chromatography-Mass Spectrometric (GC/MS) technique was completed. The plant represented twenty-one chemical compounds including Alpha-thujenes, Gamma-terpinene, Carvacrol, Thymol, Trans-caryophyllene, Aromadendrene, Alpha-humulene, Ledene, Gamma cadinene, Delta-cadinene, (-) spathulenol, Caryophullene oxid, Alpha cadinol, Iso aromadrene epoxide, Cis-alpha bisabolene, Vulgarol B, 2-ethyl-4-methyl anisole, Hexanoic acid, oct-3-en-Sylvester, Phenol, 2, 3, 5, 6 tetramethyl and Anisole, table (1). The antimicrobial activity of $T$. capitatus aromatic essential oil was analyzed on several types of pathogens using serial aromatic oil Ethanol dilutions including (50\%, 25\%, 13\%, 6\%, and 3\%). The results showed that the oil dilution of 50\% is the most effective concentration to all tested bacterial serotypes including Escherichia coli 7839 ATCC; Klebsiella pneumonia 700603 ATCC; Staphylococcus aureus 12973 ATCC, Enterococcus faecalis 12697 ATCC with an average diameter of inhibition zone according to the selected isolates reached to $28 \mathrm{~mm}$.

The inhibition zones that were recorded on the bacterial serotypes representing the minimum inhibitory concentrations (MIC), therefore, the antimicrobial effect was also evaluated on the same bacterial species including E. faecalis, K. pneumonia, E. coli; and S. saprophyticus isolated from urinary tract disorders. The results showed that the same diluted oil concentration (50\%) was also the most effective and revealed antimicrobial effect 
with an average diameter of inhibition zone stayed at $26 \mathrm{~mm}$. Escherichia coli and Enterococcus faecalis were the most isolates affected by the active oil components into both of the isolated pathogens and the bacterial serotypes (control), whereas other isolates including Staphylococcus spp. and Klebsiella pneumonia responded with less effect ( $\leq 20 \mathrm{~mm}$ and $\leq 12 \mathrm{~mm}$ ) respectively. The $T$. capitatus diluted essential oil also showed mild antimicrobial susceptibility even in low oil concentration, but, Staphylococcus saprophytic and Klebsiella pneumonia 700603 ATCC did not show any effect at the dilution of 3\%, table (1). The components of the volatile oils of the thyme plant extracted by water distillation of the aerial parts were specified by GC/MS. The results of the analysis of the components of the volatile oil extracted from the wild thyme plant showed that it contains many compounds (Table 2) and Figure (2), Because of the large number of different vehicles and their ease of handling, these vehicles were divided into six. Different chemical groups (mono-hydrocarbons), Oxygenated mono-turbine hydrocarbons, chlorocarbons hydrocarbons, bicarbonate hydrocarbons, oxybicarbicated hydrocarbons), Other non-turbine hydrocarbons may be present, and 12 compounds of wild thyme oil have been separated, representing $95.97 \%$ of the total compounds and are consistent with what was published by Miceli et al. (2006) When analyzing the volatile oil prepared from the $T$. capitatus plant that grows in southern Italy using GC/MS contains 75 compounds and Carvacrol, Thymol represents more than $50 \%$ of the volatile oil content, it was found that borneol, p-cymene, alpha-terpinene occupy the majority of the oil content as well as a relationship between these compounds where the low content of Thymol is accompanied by increased concentrations of gamma-terpinene, alpha-terpinene, myrcene, and vice versa and with what Bounatirou et al. (2007).

Table 1. Anti-effect of essential oils extracted from wild thyme against some pathogenic bacteria

\begin{tabular}{|c|c|c|c|c|c|c|}
\hline \multirow{2}{*}{$\begin{array}{l}\text { Bacterial isolates concentration: } \\
\qquad 1 \times 10^{8} \mathrm{CFU} / \mathrm{ml}\end{array}$} & \multicolumn{6}{|c|}{$\begin{array}{l}\text { Inhibition zone diameter in mm Essential oil } \\
\text { dilutions of Thymus capitatus }\end{array}$} \\
\hline & Isolates & $50 \%$ & $25 \%$ & $13 \%$ & $6 \%$ & $3 \%$ \\
\hline Escherichia coli & 2 & 26 & 24 & 22 & 22 & 22 \\
\hline Klebsiella pneumoniae & 2 & 14 & 13 & 12 & 12 & 12 \\
\hline Staphylococcus saprophyticus & 1 & 20 & 17 & 14 & 10 & 6 \\
\hline Enterococcus faecalis & 2 & 28 & 20 & 18 & 17 & 17 \\
\hline Escherichia coli 8739 ATCC & 1 & 26 & 26 & 26 & 24 & 22 \\
\hline Klebsiella pneumoniae 700603 ATCC & 1 & 12 & 10 & 10 & 8 & 6 \\
\hline Staphylococcus aureus 12973 ATCC & 1 & 20 & 18 & 18 & 17 & 17 \\
\hline Enterococcus faecalis 12697 ATCC & 1 & 28 & 24 & 24 & 20 & 18 \\
\hline
\end{tabular}

- Effectiveness on serotyping bacterial quality control, bacteria isolated from urinary tract infection.

- The inhibition results representing the mean of zone diameter in mm on Mueller-Hinton Agar. 


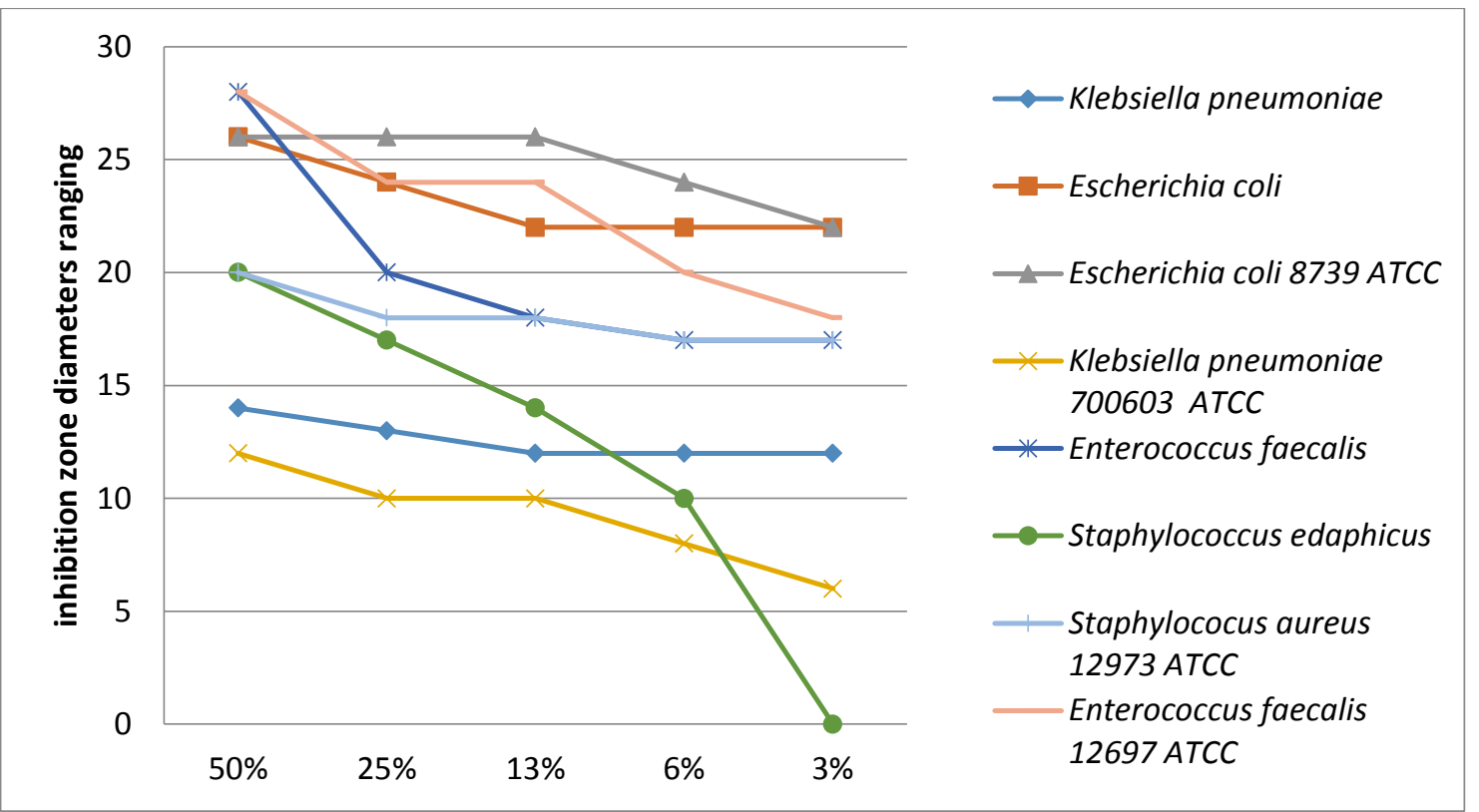

\section{Concentrations of essential oil}

Fig.1. The susceptibility of the bacterial isolates to the diluted essential oil extract of Thymus capitatus

Table 2. Results of combined gas chromatography analysis with the GC/MS mass spectrometer for oils extracted from wild thyme from the sites under study

\begin{tabular}{|c|c|c|c|c|}
\hline Percentage & \multirow{2}{*}{ Chemical name } & \multirow{2}{*}{$\begin{array}{c}\text { Chemical } \\
\text { code }\end{array}$} & \multirow{2}{*}{$\begin{array}{l}\text { Detention } \\
\text { time (min) }\end{array}$} & \multirow{2}{*}{ Number } \\
\hline Abu Daraa site & & & & \\
\hline 1.64 & Alpha-thujene & $\mathrm{C}_{10} \mathrm{H}_{16}$ & 6.8 & $\mathbf{1}$ \\
\hline 0.76 & Gamma-terpinene & $\mathrm{C}_{10} \mathrm{H}_{16}$ & 8.74 & 2 \\
\hline 48.56 & Carvcrol & $\mathrm{C}_{10} \mathrm{H}_{14} \mathrm{O}$ & 12.37 & 3 \\
\hline 1.77 & Thymol & $\mathrm{C}_{10} \mathrm{H}_{14} \mathrm{O}$ & 14.93 & 4 \\
\hline 7.41 & Trans-caryophllene & $\mathrm{C}_{15} \mathrm{H}_{24}$ & 17.77 & 5 \\
\hline- & Aromadendrene & $\mathrm{C}_{15} \mathrm{H}_{24}$ & 18.12 & 6 \\
\hline 5.20 & Alpha-humulene & $\mathrm{C}_{15} \mathrm{H}_{24}$ & 18.20 & 7 \\
\hline 6.57 & Ledene & $\mathrm{C}_{15} \mathrm{H}_{24}$ & 18.32 & 8 \\
\hline 1.93 & Gamma cadinene & $\mathrm{C}_{15} \mathrm{H}_{24}$ & 18.41 & 9 \\
\hline- & Delta- cadinene & $\mathrm{C}_{15} \mathrm{H}_{24}$ & 18.45 & 10 \\
\hline- & $(-)-$ spathulenol & $\mathrm{C}_{15} \mathrm{H}_{24} \mathrm{O}$ & 18.90 & 11 \\
\hline 6.26 & Caryophullene oxide & $\mathrm{C}_{15} \mathrm{H}_{24} \mathrm{O}$ & 19.00 & 12 \\
\hline- & Alpha cadinol & $\mathrm{C}_{15} \mathrm{H}_{26} \mathrm{O}$ & 19.54 & 13 \\
\hline 2.27 & Iso aromadrene epoxide & $\mathrm{C}_{15} \mathrm{H}_{24} \mathrm{O}$ & 19.60 & 14 \\
\hline 0.71 & Cis- alpha bisabolene & $\mathrm{C}_{15} \mathrm{H}_{24}$ & 19.70 & 15 \\
\hline
\end{tabular}


Asian Journal of Basic Science \& Research Volume 3, Issue 3, Pages 39-46, July-September 2021

\begin{tabular}{|c|c|c|c|c|}
\hline- & Vulgarol B & $\mathrm{C}_{15} \mathrm{H}_{24} \mathrm{O}$ & 19.81 & 16 \\
\hline- & 2-ethyl- 4-methyl anisole & $\mathrm{C}_{10} \mathrm{H}_{14} \mathrm{O}$ & 21.8 & 17 \\
\hline - & $\begin{array}{c}\text { Hexanoic acid, oct }-3-\text { en }- \text { zyl } \\
\text { ester }\end{array}$ & $\mathrm{C}_{14} \mathrm{H}_{26} \mathrm{O}_{2}$ & 22.78 & 18 \\
\hline 12.18 & Phenol,2,3,5,6 tertramethyl & $\mathrm{C}_{10} \mathrm{H}_{14} \mathrm{O}$ & 23.96 & 19 \\
\hline- & Anisole & $\mathrm{C}_{7} \mathrm{H}_{8} \mathrm{O}$ & 25.35 & 20 \\
\hline 12 & \multicolumn{4}{|l|}{ Number of vehicles identified } \\
\hline$\% 2.4$ & \multicolumn{4}{|l|}{ * Mono-hydrocarbon } \\
\hline$\% 50.33$ & \multicolumn{4}{|c|}{ Oxygenated mono-turbine hydrocarbons } \\
\hline$\% 21.82$ & \multicolumn{4}{|l|}{ * Cisotropin hydrocarbons } \\
\hline$\% 9.24$ & \multicolumn{4}{|c|}{ Oxygenated hydrocarbon hydrocarbons } \\
\hline- & \multicolumn{4}{|l|}{ * Dual turbine hydrocarbons } \\
\hline- & \multicolumn{4}{|c|}{ Oxygenated dual-turbine hydrocarbons } \\
\hline$\% 12.18$ & \multicolumn{4}{|l|}{ * Non-turbocharged hydrocarbons } \\
\hline$\% 95.97$ & \multicolumn{4}{|c|}{ * The total percentage of the aromatic substances that have been identified } \\
\hline
\end{tabular}

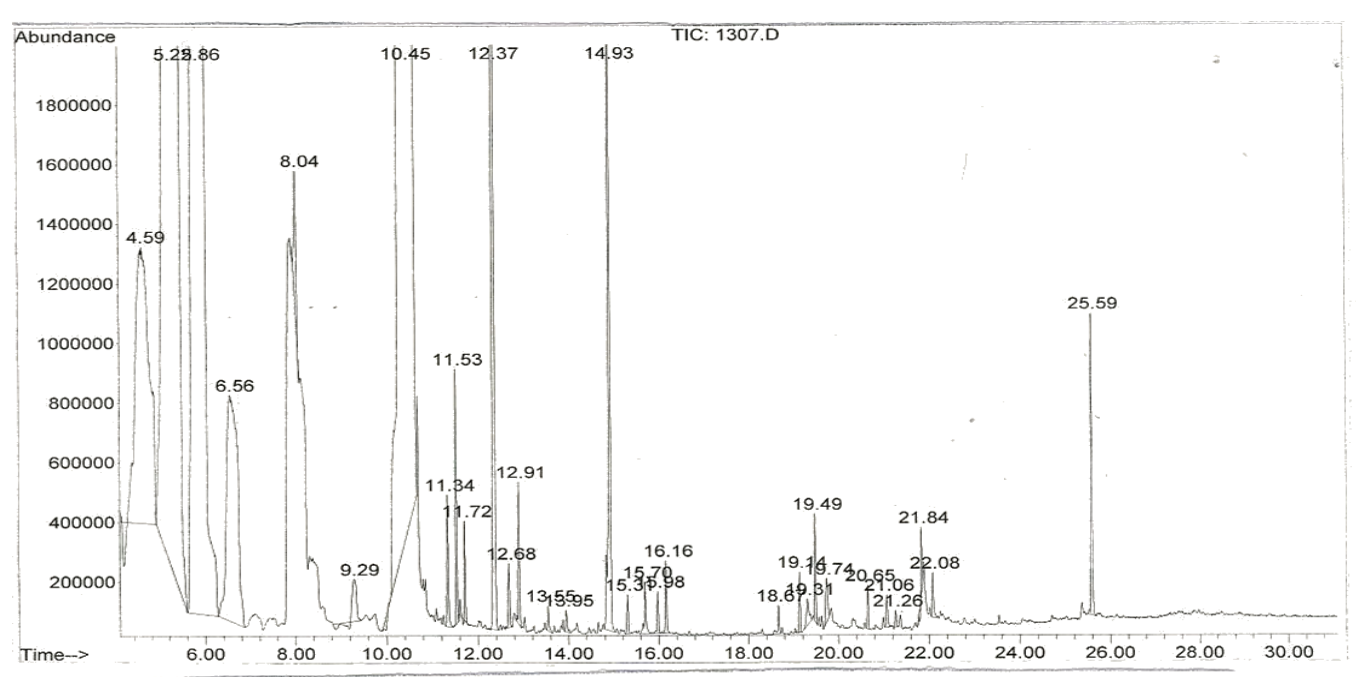

Fig.2. Separation curve for the essential oil extracted from the Thymus capitatus from the Abu Daraa site by gas chromatography connected to the mass spectrometer.

\section{Discussions}

The chemical compounds of essential oils of T. capitatus and the effect of microbial activity extract were distinguished against some pathogenic bacteria. The antimicrobial activity of essential oils of T. capitatus extract inside the laboratory against the tested microorganisms was specific as it was evaluated by the existence or absence of diameters of repression regions as a result of the effect of the oil extract, where it was noticed through the results a strong activity of the antimicrobial against the tested bacterial species where the inhibition areas reached To 28 $\mathrm{mm}$. Therefore, the results reported by the study of Deba, Xuan, Yasuda, and Tawatu, 2008; Jayari et al., 2017; 
Dzamic et al., 2015), which indicated that all essential oils are extracted from some medicinal herbs are more effective against $E$. coli and other types of bacteria. It was also observed that the concentration of the diluted oil (50\%) was most active against Escherichia coli and Enterococcus faecalis with an average diameter of the inhibition zone of $26 \mathrm{~mm}$. The diluted essential oil T. apitatus also showed slight sensitivity to antimicrobials even in low oil concentration, however, Staphylococcus saprophyticus and Klebsiella pneumoniae showed no effect at 3\% dilution These results are consistent with what he mentioned by El Abed, Kaabi et al., 2014; Jayari et al., 2017). When analyzing the essential oil extracted from T. capitatus plant using GC/MS it was found that it contains the following aromatic compounds: Carvacrol (62-83\%), p-cymene (5-17\%), gamma-terpinene (2-14\%), B-caryophyllene (1-4\%) and Ibrahimi et al. (2008). After studying and analyzing the essential oils derived from the $T$. Caramanicus plant grown in Iran by GC/MS about the presence of quantitative and qualitative differences for the oils extracted from the plant in its different phases (during vegetative growth, the beginning of flowering, complete flowering, and during the stage of fruit and seed formation) and the oil proportions were In its different phases are $(1.9 \%, 2.1 \%, 2.5 \%, 2.0 \%)$ respectively, and when analyzed by GC/MS $(37,37,29,35)$ were found aromatic compounds respectively and the main content in all samples was Carvacrol compound while aromatic compounds the other main ones are borneol, p-cymene, alpha-terpinene, Thymol, and it has been shown in this study that Carvacrol is present in a high percentage the compound Thymol is low.

\section{Conclusion}

On satellite images, it is possible to achieve compression ratios and PSNR values that are superior to the sum of the two algorithms working independently. When taken from space, satellite urban images are compressed at an average ratio of 13.22 with a peak signal to noise ratio of 32.9, while rural satellite images are compressed at an average ratio of 10.12 with a PSNR 31.29. Compared to satellite rural and urban images, Lena images have the lowest compression ratio (7.44) and the highest PSNR (34.33) of any of the satellite systems. Thus, a simplified approach of Fractal compression has been implemented to attain a basic knowledge of image analysis and identification.

\section{Declarations}

\section{Source of Funding}

This research did not receive any specific grant from funding agencies in the public, commercial, or not-for-profit sectors.

\section{Competing Interests Statement}

The authors declare no competing financial, professional and personal interests.

\section{Consent for publication}

We declare that we consented for the publication of this research work.

\section{Availability of data and material}

Authors are willing to share data and material according to the relevant needs. 
Asian Journal of Basic Science \& Research

Volume 3, Issue 3, Pages 39-46, July-September 2021

\section{References}

Adams, R. P. (2001) Identification of essential oil components by gas chromatography/quadrupole mass spectroscopy, $3^{\text {rd }}$ ed., Allured: Carol Stream, IL, 456 p.

Anon. (1996) Pharmacopiea of India (The Indian antibacterial activity assay Pharmacopiea), $3^{\text {rd }}$ ed., Govt. of India, New Delhi, Ministry of Health and Family Welfare.

Bertella A., Benlahcen K., Abouamama S., Pinto D.C.G.A., Maamar K. Kihal M. and Silva A.M.S. (2018) Artemisia herba-alba Asso. Essential oil antibacterial activity and acute toxicity. Ind. Crops \& Prod. 116: 137-143. Burt S. (2004) Essential oils: their antibacterial properties and potential applications in foods-A review. Int. J. Food Microbiol., 94:223-253. doi: 10.1016/j.ijfoodmicro..03.022.

Chouhan, S., Sharma, K. and Guleria, S. (2017) Antimicrobial Activity of Some Essential Oils, Present Status and Future Perspectives. Medicines, 4(58): 1-21. doi: 10.3390/medicines4030058.

Deba, F., Xuan, T. D., Yasuda, M., \& Tawatu, S. (2008) Chemical composition and antioxidant, antibacterial and antifungal activities of the essential oils from Bidens pilosa. Linn Var Radiata. Food Control, 19, 346-352.

Dzamic, A.M. Nikolic, B.J. Giweli, A.A. MiticCulafic, D.S. Sokovic, M.D. Ristic, M.S. Knezevic Vukcevic J.B. and Marin P.D. (2015) Libyan Thymus capitatus essential oil: antioxidant, antimicrobial, cytotoxic and colon pathogen adhesion inhibition properties, Journal of Applied Microbiology, ISSN 1364-5072.

El Abed, N., Kaabi, B., Smaali, M. I., Chabbouh, M., Habibi, K., Mejri, M., \& Ben Hadj Ahmed, S. (2014) Chemical composition, antioxidant and antimicrobial activities of Thymus capitata essential oil with its preservative effect against Listeria monocytogenes inoculated in minced beef meat. Evidence-Based Complementary and Alternative Medicine, 1-11.

Holley R.A., Patel D. (2005) Improvement in shelf-life and safety of perishable foods by plant essential oils and smoke antimicrobials, Food Microbiol., 22: 273-292. doi: 10.1016/j.fm.2004.08.006.

Jayari, A. El Abed, N. Jouini, A. Abdul-Wahab, O. M. S. Maaroufi, A. Hadj Ahmed, S. (2017) Antibacterial activity of Thymus capitatus and Thymus algeriensis essential oils against four food-borne pathogens inoculated in minced beef meat, Food Saf., 38: e12409.

Lakehal, S., et al., (2016) Essential Oil Composition and Antimicrobial Activity of Artemisia herba-alba Asso Grown in Algeria. Med chem (Los Angeles), 6(6): 435-439.

Lis-Balchin M., Deans S.G., Eaglesham E. (1998) Relationship between bioactivity and chemical composition of commercial essential oils, Flavour Fragr. J., 13: 98-104. doi: 10.1002/(SICI)1099-1026.

Marino M., Bersani C., Comi G. (2001) Antimicrobial activity of the essential oils of Thymus vulgaris L. measured using a bioimpedimetric method. Int. J. Food Microbiol., 67: 187-195. doi: 10.1016/S0168-1605(01)00447-0.

Rauha J.P., et al., (2000) Antimicrobial effects of Finnish plant extracts containing flavonoids and other phenolic compounds. Int. J. Food Microbiol., 56: 3-12. doi: 10.1016/S0168-1605(00)00218-X.

Salvagnini, L. E.; Oliveira, J. R. S.; Santos, L. E. D.; Moreira, R. R. D. and Pietro, R. C. L. (2008) Evaluation of the antibacterial activity of Myrtus communis L. (Myrtaceae) leaves. Rev. Bra. de Farmacognosia, 18(2): 241-244. 